\title{
Compound-Type Hybrid Energy Storage System and Its Mode Control Strategy for Electric Vehicles
}

\author{
Bin Wang*, Jun $\mathrm{Xu}^{\dagger}$, Binggang Cao*, Qiyu $\mathrm{Li}^{*}$, and Qingxia Yang* \\ ${ }^{\dagger *}$ State Key Laboratory for Manufacturing Systems Engineering, School of Mechanical Engineering, Xi’an Jiaotong \\ University, Xi' an, China
}

\begin{abstract}
This paper proposes a novel compound-type hybrid energy storage system (HESS) that inherits the unique advantages of both battery/supercapacitor (SC) and the SC/battery HESSs for electric vehicles (EVs). Eight operation modes are designed to match this system. A mode control strategy is developed for this HESS on the basis of these modes, and five classes of operation modes are established to simplify this strategy. The mode control strategy focuses on high operating efficiency and high power output. Furthermore, the compound-type HESS is designed such that the SC is the main priority in braking energy absorption. Thus, this HESS can operate efficiently and extend battery life. Simulation results also show that the compound-type HESS can not only supply adequate power to the motor inverter but can also determine suitable operation modes in corresponding conditions. Experimental results demonstrate that this HESS can extend battery life as well. The overall efficiency of the compound-type HESS is higher than those of the battery/SC and the SC/battery HESSs.
\end{abstract}

Key words: DC-DC converter, Electric vehicles, Hybrid energy storage system, Mode control strategy, Supercapacitor

\section{INTRODUCTION}

New energy vehicles have received much attention as a promising solution to the energy crisis and to environmental pollution [1]-[4]. In particular, electric vehicles (EVs) are advantageous over other new energy vehicles in the following ways: no fuel consumption, reduced daily traveling costs, and little noise [5]. Batteries are common among all of the energy storage systems (ESSs) used in EVs [1], [6]-[8]. However, the power density of a battery should be adequately high to meet peak power demand. Current battery technology can satisfy the requirements of EVs, but the size and the high cost of batteries may be unacceptable [1], [6]. In addition, ESSs often receive instantaneous power demands. Thus, batteries must operate under frequent charge and discharge. These processes adversely affect battery life [9]. As a result, battery cells are difficult to balance under extreme working conditions [10]. These drawbacks mainly drive the development of auxiliary energy sources and the design of

Manuscript received Jan. 15, 2015; accepted Feb. 21, 2015 Recommended for publication by Associate Editor Jonghoon Kim.

†Corresponding Author: xujunx@mail.xjtu.edu.cn

Tel: +86 82668835, Xi'an Jiaotong University

*State Key Laboratory for Manufacturing Systems Engineering, School of Mechanical Engineering, Xi'an Jiaotong University. energy management strategies for extending battery life [4], [7], [11], [12].

Hybrid energy storage systems (HESSs) that combine batteries with supercapacitors (SCs) have been proposed to address the aforementioned drawbacks [13]-[15]. SCs can be used as auxiliary equipment to absorb braking energy during regenerative braking and to prevent batteries from being subjected to peak power under low-energy and high-power densities [16], [17]. Thus, battery life can be extended in EV applications, especially under start-stop or acceleration [11], [17]. A key factor in designing a HESS that performs perfectly is to maximize the energy stored in SCs [6], [18]. In previous studies, SCs were used as low-pass filters in passive parallel configuration [11], [18]. This configuration did not employ DC-DC converters; thus, there was no energy loss in power converters. Furthermore, passive parallel configuration was low-cost. However, the energy stored in the SC could not be utilized effectively.

Multiple or cascaded converter configurations have been recommended to maximize the energy stored in SCs [17], [19]. In the two configurations, both battery and SC voltages can be kept lower than motor inverter voltage. Thus, battery cells can be easily balanced. However, two or more full-size converters must be incorporated into these configurations to 
match the battery and the SC; as a result, the cost of the power converter is high. The energy from either a battery or a SC should also be converted with a DC-DC converter at least once to reduce the operating efficiency of the entire system. The efficiency is another key factor in HESS design. Numerous studies investigated either optimal control or energy management strategies to improve the operating efficiencies under the two configurations. However, these studies fail to reduce the times of energy converted [17], [20]-[24]. Multi-output DC-DC converter topologies have also been generated on the basis of multiple or cascaded converter configurations [25], [26]. Considering the cost and the efficiency, these configurations may be not suitable for the application of HESS in EVs.

Size should also be considered carefully when designing a suitable HESS for EVs [27], [28]. An ESS with a single DCDC converter configuration is preferred due to the small size and low cost of the DC-DC converter [29]-[31]. Moreover, the energy from either the battery or the SC is converted only once in this configuration. Thus, the operating efficiency of the entire system can be increased. Such configurations include battery/SC [32], [33], SC/battery [31], [34], hybrid topology [6], and semi-active HESSs [1], [32]. The SC/battery HESS utilizes SCs with low nominal voltages, but this system requires a large DC-DC converter. On the contrary, a small DC-DC converter is adequate for the battery/SC HESS, but battery energy cannot be used as effectively. The hybrid topology and the semi-active HESSs were studied in [1] and [6]. Both systems incorporated only one power diode into the battery/SC HESS, thereby increasing the number of operation modes. However, these system cannot actively switch to low-power mode until the available energy for use in the SC is reduced. This scenario limits the operating efficiency of the HESS.

In this paper, a novel compound-type HESS is proposed. And the mode control strategy is developed for this HESS. This paper is organized as follows: Section II presents the specific configuration of the compound-type HESS. Section III discusses the operation modes of this HESS. Section IV presents the design of the mode control strategy. Section $\mathrm{V}$ discusses the simulation results. Section VI details the experimental verification process. Section VII provides the main conclusion.

\section{DESIGN OF THE COMPOUND-TYPE HESS}

The major disadvantage of the conventional battery/SC [7], [28] and the SC/battery HESSs [11] [31], [34] is that an energy source must operate alongside the DC-DC converter, thus aggravating the energy loss in the power converter. The hybrid topology HESS that incorporates an additional power diode into the battery/SC HESS solves the aforementioned problem [6]. Pure battery mode is passively activated by the

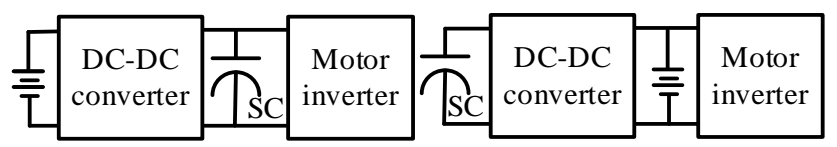

(a) Battery/SC HESS.

(b) SC/battery HESS.



(c) Hybrid topology HESS.

Fig. 1. HESSs with single DC-DC converter configuration.
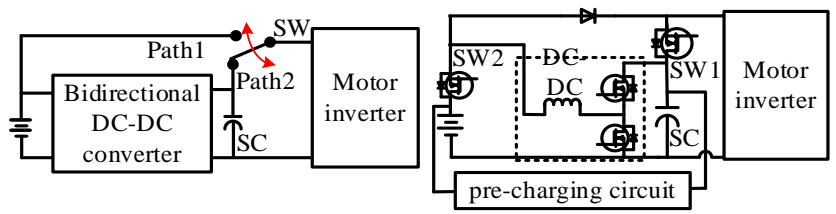

(a) Original concept.

(b) Specific configuration.

Fig. 2. Compound-type HESS.

clamping voltage of the SC. In other words, the pure battery mode of the hybrid topology HESS cannot switch actively. Fig. 1 shows the three types of HESSs.

The proposed HESS combines the advantages of the battery/SC and the SC/battery HESSs. This proposed HESS is labelled as the compound-type HESS in this study. The proposed compound-type HESS has many advantages, including the following: (1) this HESS can be actively switched to pure battery mode to meet low power demands with the SC/battery HESS operation type; and (2) the SC can be used directly to satisfy peak power demands with the battery/SC HESS operation type. The original concept of the compound-type HESS is shown in Fig. 2(a) as a brief introduction. The HESS operates with a selector switch (SW) to select operation types actively. When the SW selects Path1, the HESS operates as the SC/battery HESS type. Otherwise, the HESS operates under the battery/SC HESS type.

The proposed HESS must be controlled automatically to perform functions similar to the circuit in Fig. 2(a) as a HESS in the EV. To extend battery life, batteries should avoid direct recharge during regenerative braking. Furthermore, the power outputs of the batteries and of the SC should be controlled separately. The novel compound-type HESS is designed under a specific configuration to meet all of these requirements, as depicted in Fig. 2(b). Under this configuration, the nominal voltage of the batteries is approximately $50 \%$ of the maximum SC voltage. Hence, the SC can deliver more than $75 \%$ of the stored energy. The $50 \%$ discharge ratio is selected because $\mathrm{V}_{\mathrm{SC}}$ decreases exponentially in a constant power application. Meanwhile, power demand is related to voltage and current, and the SC 
current increases exponentially. The system is inefficient when this voltage is less than $50 \%$ [6]. If either the battery or the SC voltage is low, overall system efficiency may decrease.

In Fig. 2(b), SC voltage is generally higher than that of the batteries. When SW1 is ON, either the battery/SC HESS or the SC/battery HESS operation type is selected. Both SW1 and SW2 are OFF during regenerative braking. Furthermore, braking energy can be injected directly into the SC to extend battery life. However, the SC voltage may be less than the battery voltage, thereby posing potential risk to the SC and to the batteries. Thus, SW2 is OFF. The HESS should use the pre-charging circuit to charge the SC in this condition. Meanwhile, the SC is sized to satisfy the design goal. This goal involves using the SC to satisfy peak power demands. The SC for the SD-EV developed in our laboratory must provide power constantly (equal to the peak power demand of the motor) at least every minute to ensure the gradeability of the SD-EV. Other methods for optimizing SC size can be derived from [1] and [6].

\section{OPERATION MODES OF THE COMPOUND-TyPE HESS}

Many operation modes can be obtained by the unique configuration of the compound-type HESS. The power demands of the EV may vary in different driving conditions. Thus, the operation modes of this HESS must match these conditions with their corresponding mode control strategies. The ON/OFF states of SW1 and SW2, the states of charge (SOCs) or the voltages of the energy sources, and the operation modes of the DC-DC converter are considered comprehensively in the investigation of these operation modes. In this section, the operation modes and the energy flows of the compound-type HESS are detailed along with the ON/OFF states of SW1 and SW2.

When SW1 is ON, three operation modes can be obtained. Fig. 3(a) illustrates the energy flow of the pure SC mode, wherein the SC voltage should be higher than the upper limit (the SOC of SC is higher than 0.95). Moreover, the batteries need not supply power to the motor inverter. Thus, SW2 and the DC-DC converter are OFF. Fig. 3(b) exhibits the energy flow of the hybrid output mode. In this mode, SW2 is ON and the DC-DC converter operates in boost mode. Both the batteries and the SC provide power to the motor inverter. Fig. 3(c) displays recharge mode I. In this mode, the batteries recharge the SC and the DC-DC converter operates in boost mode.

When SW1 is OFF, the HESS can operate in either output or input modes. Figs. 4(a) to 4(c) display the output modes. The pure battery mode can be initiated to meet the low power demands of the motor inverter. When the SC voltage is lower



(a) Pure SC mode.

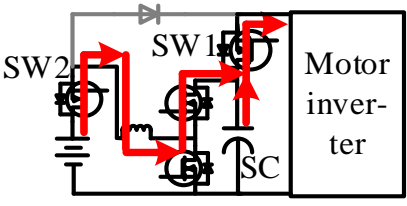

(b) Hybrid output mode.

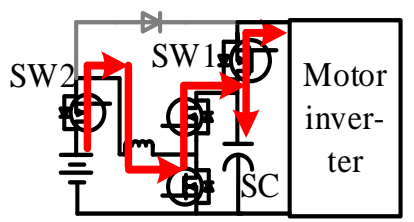

(c) Recharge mode I.

Fig. 3. Operation modes when SW1 is ON.

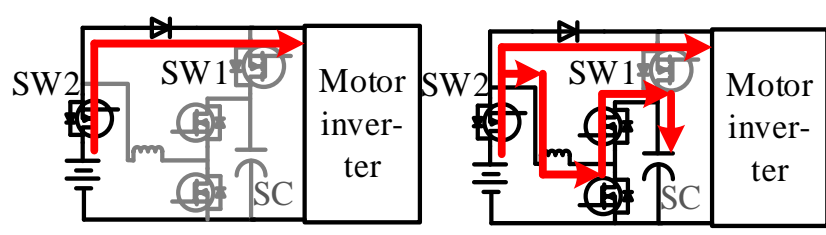

(a) Pure battery mode.

(b) Recharge mode II.



(c) Low power mode.

Fig. 4. Operation modes when SW1 is OFF.

than 0.5 , recharge mode II can be activated to meet the low power demands. Low power mode can be used when battery SOC is less than 0.1. In this condition, the DC-DC converter bucks the SC voltage and the EV must be driven at low speed because the HESS provides limited power.

The input modes are applied in regenerative braking. In this condition, SW2 must be OFF. Figs. 5(a) to 5(b) depict the operation modes. The pure SC recycle mode should be selected when the SC voltage is lower than the upper limit. Otherwise, the hybrid recycle mode is applied.

\section{Mode Control StRategy}

The schematic of the mode control system is displayed in Fig. 6. The input signals of the data acquisition system are the power demand of the motor, the currents, and the voltages of the batteries and of the SC. The control system calculates the power demand of the compound-type HESS, the SOCs of the batteries, and the SC. A suitable operation mode is selected, and the power distribution is implemented by controlling SW1, SW2, and the DC-DC converter. 


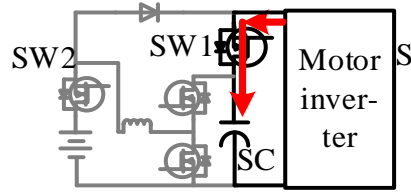

(a) Pure SC recycle mode.

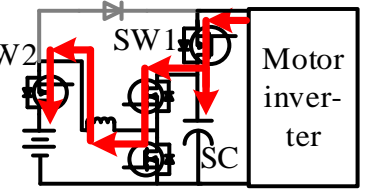

(b) Hybrid recycle mode.
Fig. 5. Operation modes when SW1 and SW2 are OFF.

\begin{tabular}{|c|c|c|c|c|c|c|c|}
\hline $\begin{array}{c}\text { power } \\
\text { demand of }\end{array}$ & \multirow{4}{*}{$\begin{array}{c}\text { Data } \\
\text { acqui- } \\
\text { sition } \\
\text { system }\end{array}$} & $\begin{array}{c}\text { power } \\
\text { demand }\end{array}$ & \multirow{4}{*}{$\begin{array}{c}\text { Select } \\
\text { a } \\
\text { suitable } \\
\text { mode }\end{array}$} & $\begin{array}{c}\text { voltage } \\
\text { signal }\end{array}$ & \multirow{4}{*}{$\begin{array}{l}\text { drive } \\
\text { cir- } \\
\text { cuit }\end{array}$} & $\begin{array}{c}\text { SW1 } \\
\text { (ON/OFF) }\end{array}$ & \multirow{4}{*}{$\begin{array}{l}\text { Power } \\
\text { distri- } \\
\text { bution } \\
\text { of } \\
\text { different } \\
\text { mode }\end{array}$} \\
\hline $\begin{array}{c}\text { the motor } \\
\text { voltage, } \\
\text { current }\end{array}$ & & Bat & & $\begin{array}{c}\text { voltage } \\
\text { signal }\end{array}$ & & $\begin{array}{c}\text { SW2 } \\
(\mathrm{ON} / \mathrm{OFF})\end{array}$ & \\
\hline of the bat & & SOC & & $\overrightarrow{\mathrm{PWM}}$ & & DC-DC & \\
\hline $\begin{array}{l}\text { voltage, } \\
\text { current } \\
\text { of the SC }\end{array}$ & & $\begin{array}{c}\mathrm{SC} \\
\mathrm{SOC} \\
\end{array}$ & & $\begin{array}{c}\text { voltage } \\
\text { signal }\end{array}$ & & $\begin{array}{c}\text { (power out) } \\
\text { Pre-chrging } \\
\text { (ON/OFF) }\end{array}$ & \\
\hline
\end{tabular}

Fig. 6. Schematic of the mode control system.

\section{A. Modeling}

The power demand of the HESS, battery SOC, and the SOC of the SC should be calculated in the mode control system. The driving cycle of an EV is complex, and power demand is difficult to calculate accurately by incorporating unwanted disturbances. Thus, nonlinear disturbances are ignored in the simulation model.

$$
P_{H E S S}^{\text {dem }}=\left(P_{f}+P_{\text {acc/dec }}+P_{c l m b}+P_{a d}\right) / \eta_{\text {motor }} \eta_{\text {inverter }}
$$

where $P_{H E S S}^{d e m}=U_{d c} I_{d c}$ is the power demand of the HESS; $\boldsymbol{P}_{f}$ is the power demanded to meet the rolling resistance of the wheel; $P_{a c c / d e c}$ is the power demanded by acceleration or deceleration; and $P_{c l m b}$ and $P_{a d}$ are the power demands to facilitate climbing and generate aerodynamic drag force, respectively.

The battery and SC models are established with resistance-capacitance (RC) equivalent circuits [35], [36]. Fig. 7 shows the two RC equivalent circuits. The equivalent circuit of the battery consists of capacitors $\left(C_{b}\right.$ and $\left.C_{c}\right)$ and three resistors $\left(R_{e}, R_{t}\right.$, and $\left.R_{c}\right)$. The relationships among the voltages of $C_{b}$ and $C_{c}$ and the three resistors are indicated in Eq. (2). The output voltage of the single battery is expressed in Eq. (3), and the calculation of battery SOC is described in Eq. (4) [37].

$$
\begin{aligned}
& \left(\begin{array}{c}
V_{C b}^{\prime} \\
V_{C c}^{\prime}
\end{array}\right)=\left(\begin{array}{ll}
\frac{-1 / C_{b}}{\left(\mathrm{R}_{\mathrm{e}}+R_{c}\right)} & \frac{-1 / C_{b}}{\left(\mathrm{R}_{\mathrm{e}}+R_{c}\right)} \\
\frac{-1 / C_{c}}{\left(\mathrm{R}_{\mathrm{e}}+R_{c}\right)} & \frac{-1 / C_{c}}{\left(\mathrm{R}_{\mathrm{e}}+R_{c}\right)}
\end{array}\right)\left(\begin{array}{c}
V_{C b} \\
V_{C c}
\end{array}\right)+\left(\begin{array}{c}
\frac{-\mathrm{R}_{\mathrm{e}} I_{b a t}}{C_{b}\left(\mathrm{R}_{\mathrm{e}}+R_{c}\right)} \\
\frac{-\mathrm{R}_{\mathrm{e}} I_{b a t}}{C_{c}\left(\mathrm{R}_{\mathrm{e}}+R_{c}\right)}
\end{array}\right) \\
& {\left[V_{\text {out }}\right]=\left[\begin{array}{ll}
\frac{R_{c}}{\left(\mathrm{R}_{\mathrm{e}}+R_{c}\right)} \frac{R_{e}}{\left(\mathrm{R}_{\mathrm{e}}+R_{c}\right)}
\end{array}\right]\left[\begin{array}{l}
V_{C b} \\
V_{C c}
\end{array}\right]-\left[R_{t}+\frac{R_{c} R_{e}}{\left(R_{c}+R_{\mathrm{e}}\right)}\right] I_{b a t}} \\
& S O C_{b a t}=\frac{1}{21}\left(20 \operatorname{SOC}\left(V_{C b}\right)+\operatorname{SOC}\left(V_{C c}\right)\right) \cdot
\end{aligned}
$$

The SC equivalent circuit consists of a capacitor with constant capacitance $\left(C_{0}\right)$ and a capacitor with variable capacitance $\left(C_{v}\right) . C_{v}$ is linear with SC voltage, as expressed in

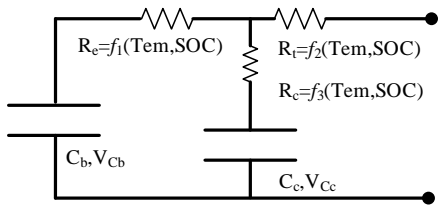

(a) Battery equivalent circuit.

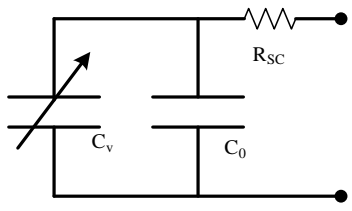

(b) SC equivalent circuit.
Fig. 7. Equivalent circuits of the batteries and of the SC.

TABLE I

Classification OF THE Operation Modes

\begin{tabular}{ccc}
\hline Number & Classification & DC-DC converter \\
\hline 1 & Lossless mode & No operation \\
2 & Economy mode & Boost mode (peak efficiency) \\
3 & Power mode & Boost mode (upper limit) \\
4 & Braking mode & No operation \\
5 & Emergency mode & Buck mode (power limit) \\
\hline
\end{tabular}

Eq. (5). A multi-partition of the SC voltage is utilized to calculate the SOC of the SC. This multi-partition assumes that the average variation in capacitance from $V_{n}$ to $V_{n+1}$ is $C_{1}$. The calculation of the SOC of the SC is expressed in Eqs. (6) to (8) [38].

$$
\begin{gathered}
C_{v}=K_{v} V_{S C} \cdot \\
V_{\text {variation }}=\left(V_{n}-V_{n-1}\right)=\left(V_{n+1}-V_{n}\right)=V_{S C}^{\max } / k . \\
S O C_{S C}=\frac{1}{2} C_{0} V^{2}+\frac{1}{2} C_{1}\left(V_{1}-V_{0}\right)^{2}+\frac{1}{2} * 2 C_{1}\left(V_{2}-V_{1}\right)^{2} \\
+\ldots+\frac{1}{2} * n C_{1}\left(V_{n}-V_{n-1}\right)^{2}+\ldots+\frac{1}{2} * k C_{1}\left(V_{k}-V_{k-1}\right)^{2} \\
\operatorname{SOC}_{S C}=\frac{1}{2} C_{0} V^{2}+\frac{1}{2} C_{1} \frac{(1+k) k}{2} V_{\text {variation }}^{2} .
\end{gathered}
$$

\section{B. Mode Control Strategy}

The compound-type HESS utilizes eight operation modes in addition to the pre-charging mode. Selecting a suitable mode to match the corresponding driving condition is key to mode control strategy. This strategy is designed with mode switch rules and power management strategy. Given that the mode switch may be either active or passive, the energy flows varies according to different modes. Even power distributions are dissimilar in the same operation mode. A power management strategy may be complicated to design. Furthermore, this strategy is directly related to the power output of the DC-DC converter; therefore, five classes of operation modes are proposed to control this converter effectively and clearly. The classification of the operation modes is shown in both Table I and Fig. 8(a). The efficiency of the DC-DC converter is presented in Fig. 8(b). The state diagram of the mode control strategy is presented in Fig. 8(c).

The operation modes and the control of the power output of the DC-DC converter are easy to determine on the basis of the five classes of these modes. Thus, mode switch rules and a power management strategy can be easily designed. 


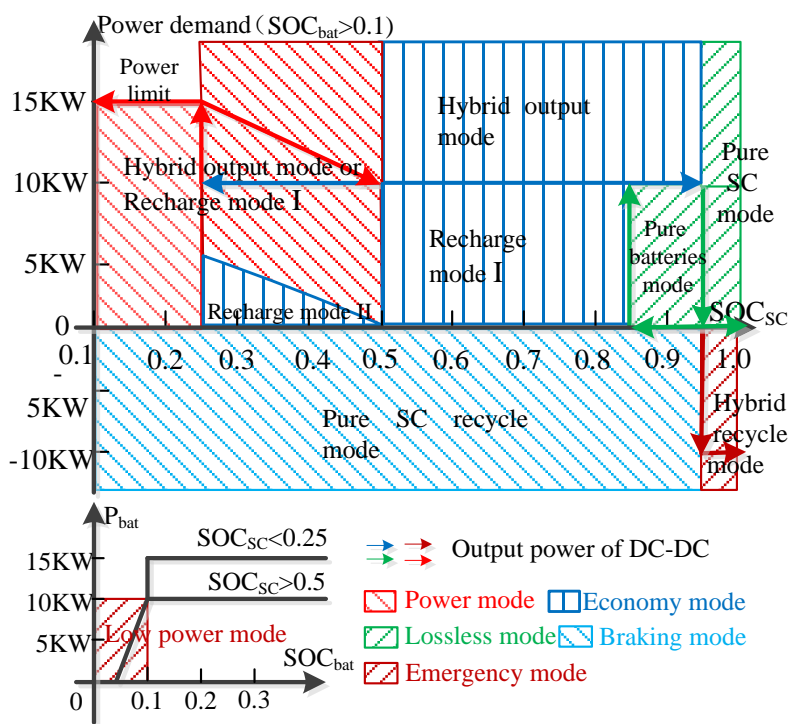

(a) Mode control strategy.

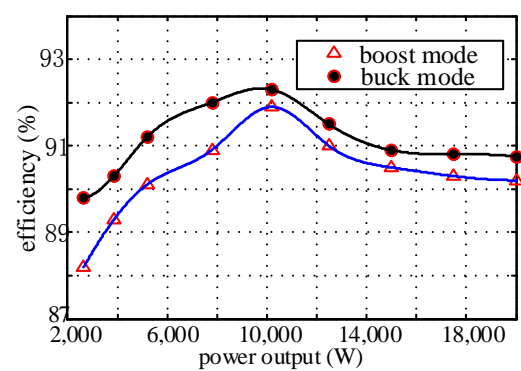

(b) Efficiency of DC-DC converter in EVs.

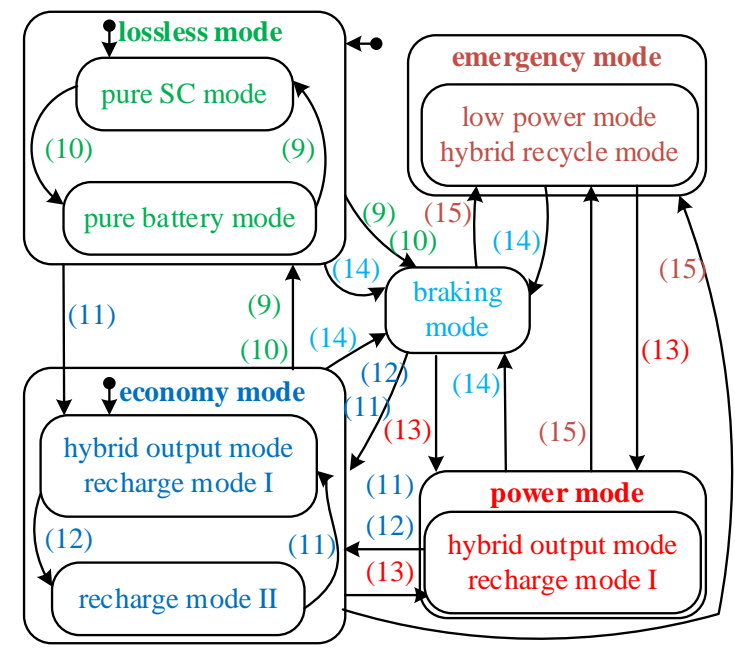

(c) State diagram.

Fig. 8. Mode control strategy and DC-DC efficiency.

The class of lossless mode includes the pure SC and pure battery modes. The lossless mode is ideal because the operation does not include the DC-DC converter. The switch rules and power distributions of the pure SC and pure battery modes are expressed in Eqs. (9) and (10), respectively.

$$
P_{S C}=P_{H E S S}^{d e m} \cdot\left[\left(S O C_{S C} \geq 0.95\right) \wedge\left(S O C_{b a t} \geq 0.1\right) \wedge\left(P_{H E S S}^{d e m} \geq 0\right)\right] \text {. (9) }
$$

$$
\begin{aligned}
P_{\text {bat }}=P_{H E S S}^{\text {dem }} & \cdot\left[\left(S O C_{\text {bat }} \geq 0.1\right) \wedge\left(0.85 \leq S O C_{\mathrm{SC}}<0.95\right)\right. \\
& \left.\wedge\left(0<P_{H E S S}^{\text {dem }} \leq 10 \mathrm{~kW} / \eta_{D C-D C}^{\text {peak }- \text { efficience }}\right)\right]
\end{aligned}
$$

The class of economy mode includes the hybrid output mode, recharge mode I, and recharge mode II. In this mode class, the DC-DC converter operates at peak efficiency. In hybrid output mode and in recharge mode I, the power output of the batteries is $P_{b a t}=10 \mathrm{~kW} / \eta_{D C-D C}^{\text {peak-efficience }}$ ). The SC either provides or absorbs the additional power. The switch rules of the hybrid output mode and of recharge mode I are determined using Eq. (11).

$$
\begin{gathered}
\left(S O C_{\text {bat }} \geq 0.1\right) \wedge\left(P_{H E S S}^{d e m}>0\right) \wedge\left\{\left(0.5 \leq S O C_{\mathrm{SC}}<0.85\right)\right. \\
\left.\vee\left[\left(0.85 \leq S O C_{\mathrm{SC}}<0.95\right) \wedge\left(P_{H E S S}^{d e m}>10 \mathrm{~kW}\right)\right]\right\}
\end{gathered} .
$$

In recharge mode II, the power output of the batteries is $P_{b a t}=P_{H E S S}^{d e m}+10 \mathrm{~kW} / \eta_{D C-D C}^{\text {peak-efficience }}$ and the power input of the SC is $10 \mathrm{~kW}$. $P_{b a t}$ must be less than the upper limit. Moreover, the switch rule of recharge mode II is expressed in Eq. (12).

$$
\begin{aligned}
& S O C_{\text {bat }} \geq 0.1 \wedge\left(P_{\text {HESS }}^{\text {dem }}>0\right) \wedge\left[\left(0.25 \leq S O C_{\mathrm{SC}}<0.5\right) .\right. \\
& \left.\wedge\left(P_{\text {bat }}<P_{\text {bat }}^{\text {upper }}\right)\right] \quad\left(P_{\text {bat }}^{\text {upper }}=-20 S O C_{S C}+20\right)
\end{aligned} .
$$

The class of power mode includes the hybrid output mode and recharge mode I. In this mode class, the power output of the batteries is $P_{b a t}=P_{b a t}^{u p p e r}$. Thus, the power output of the DC-DC converter is $P_{D C-D C}=P_{b a t}^{u p p e r} / \eta_{D C-D C}$. The SC either provides or absorbs excess power. The switch rule of the power mode is expressed in Eq. (13).

$$
\begin{aligned}
& S O C_{\text {bat }} \geq 0.1 \wedge\left(P_{H E S S}^{\text {dem }}>0\right) \wedge\left\langle\left(S O C_{\mathrm{SC}} \leq 0.25\right)\right. \\
& \left.\vee\left\{\left(0.25 \leq S O C_{\mathrm{SC}}<0.5\right) \wedge\left[10 \mathrm{KW} / \eta_{D C-D C}^{\text {peak }- \text { efficience }}>\left(P_{\text {bat }}^{\text {upper }}-P_{H E S S}^{\text {dem }}\right)\right]\right\}\right\rangle
\end{aligned}
$$

The braking mode is simple because the SC absorbs braking power perfectly. All regenerative braking is incorporated into the SC when SOC is less than 0.95. Thus, the batteries are prevented from direct recharge. The switch rule is expressed in Eq. (14).

$$
\left(P_{H E S S}^{d e m}<0\right) \wedge\left(S O C_{S C}<0.95\right) .
$$

The class of emergency mode includes two special operation modes: low power and hybrid recycle. These modes should be used as sparingly as possible to extend battery life. In the emergency mode, the recharge power supplied by the DC-DC converter to the batteries is set to 10 $\mathrm{kW}$. The power output of the batteries should be limited to less than $5 \mathrm{~kW}$ when these devices provide power to the motor inverter. The switch rule is determined using Eq. (15).

$$
\left[S O C_{b a t}<0.1, P_{H E S S}^{d e m}>0\right] \vee\left[\left[S O C_{S C}>0.95, P_{H E S S}^{d e m}<0\right] .\right.
$$

The upper limit of battery power output $\left(S O C_{b a t}>0.1\right)$ is $10 \mathrm{~kW}$ when the SOC of the SC is higher than 0.5. Therefore, the SC can successfully limit the power output of the batteries. When the SOC of the SC is less than 0.5, the batteries should supply additional power. Eq. (12) is applied to limit the power output of the batteries. The maximum battery power 
TABLE II

IMPORTANT PARAMETERS OF THE COMPOUND-TyPE HESS

\begin{tabular}{cc}
\hline Items & Values \\
\hline SC & $400 \mathrm{~V}(5 * 80 \mathrm{~V}$ 96 F in series $)$ \\
Batteries & $208 \mathrm{~V}(3.2 \mathrm{~V} 80$ Ah in series $)$ \\
DC-DC converter & Peak efficiency (9.8 $10.2 \mathrm{~kW})$ \\
Total mass of the EV & $1350 \mathrm{Kg}$ \\
motor & $30 \mathrm{~kW}(\mathrm{PMSM})$ \\
Radius of the wheel & $0.29 \mathrm{~m}$ \\
\hline
\end{tabular}

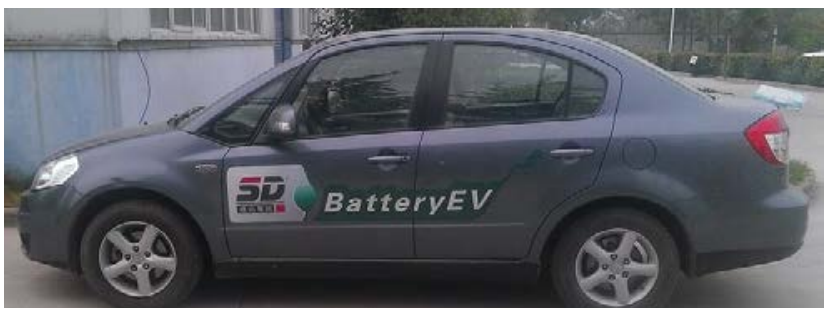

(a) SD-EV.

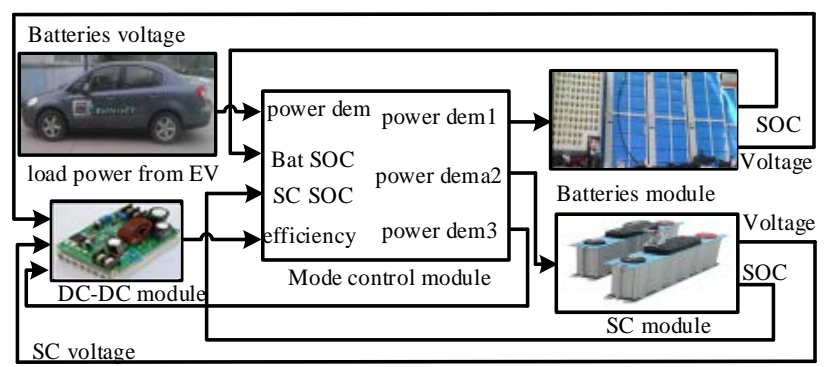

(b) Simulation modules.

Fig. 9. Simulation modules based on SD-EV.

output $\mathrm{s}$ is $15 \mathrm{~kW}$. This setting is applied when the SOC of the SC is 0.25 .

If regenerative braking must be continuous and when both the battery and the SC are fully charged, then braking resistance can be considered in the process of absorbing the excess energy under regenerating mode.

\section{Simulation Results}

A simulation model that is based on SD-EV is developed to validate the compound-type HESS. The important parameters of this HESS and of the SD-EV are presented in Table II. The simulation modules of the compound-type HESS are presented in Fig. 9. Three types of power demands (highlighted in Fig. 10) are chosen to reflect the different operating characteristics of the HESS in the New York City Cycle (NYCC), the Extra Urban Driving Cycle (EUDC), and the Japanese 1015 Driving Cycle (J1015).

Figs. 11(a) and 11(b) show the simulation results in the NYCC. The hybrid output mode is activated when $0.85 \leq S O C_{\mathrm{SC}}<0.95$. Moreover, the pure SC mode is selected when the SOC of the SC is higher than 0.95. The
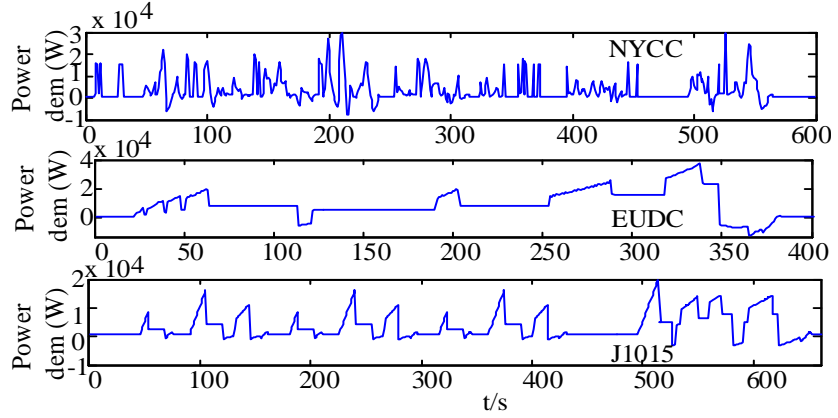

Fig. 10. Three types of power demands.

classes of the economy, lossless, and braking modes are also implemented in the NYCC. The hybrid output mode is selected when the power is higher than $10 \mathrm{~kW}$. The SC is used to meet the high peak power demand. Thus, the power output of the batteries is maintained at an appropriate level. The SC also absorbs all of the braking energy so that the batteries avoid direct recharge in the braking mode. Therefore, battery life is extended.

Figs. 11(c) and 11(d) show the simulation results in the EUDC and in the J1015, respectively. The maximum power demand in the EUDC is approximately twice that of the power demand in the J1015. Thus, the SC provides additional energy to meet the peak power demand. In the process, the SC SOC drops quickly. When the SC SOC is less than 0.5 and the power demand is high, the power mode is utilized. At the end of the EUDC, recharge mode II is selected to compensate the SC SOC. Pure battery mode is usually used in J1015 because the power demand is low, and the SC SOC value observed in this region is in the range of [0.85, 0.95].

The simulation results suggest that the classes of the lossless and economy modes are utilized to reduce energy losses in the DC-DC converter. The power mode is selected only when the SC SOC is less than 0.5 and the power demand is high. This mode ensures the HESS can provide adequate power to the motor inverter. In addition, the SC absorbs all of the braking energy to extend battery life. Therefore, the proposed compound-type HESS balances high operating efficiency with high power output using its mode control strategy.

\section{EXPERIMENT VERIFICATION}

In many HESS studies, researchers employ a scaled-down platform and usually perform experiments with electronic load and power supply. The experimental results can reflect the representative characteristics of HESS. Thus, the effectiveness of the HESSs in combination with their control strategies can be confirmed by such findings. For example, [6] and [33] performed experiments in this manner. Hence, we also conducted our experiment similarly. The 
Economy mode Economy mode Braking mode (Hybrid output mode) ( Recharge mode I (Pure SC recycle mode)

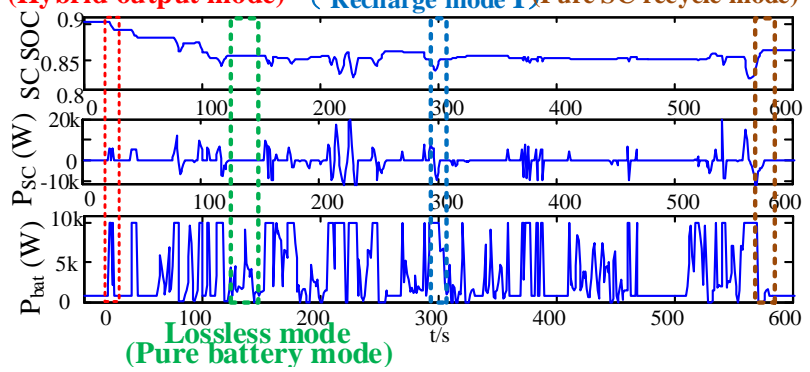

(a) Simulation results in the NYCC (the initial SOC of the SC is 0.91).

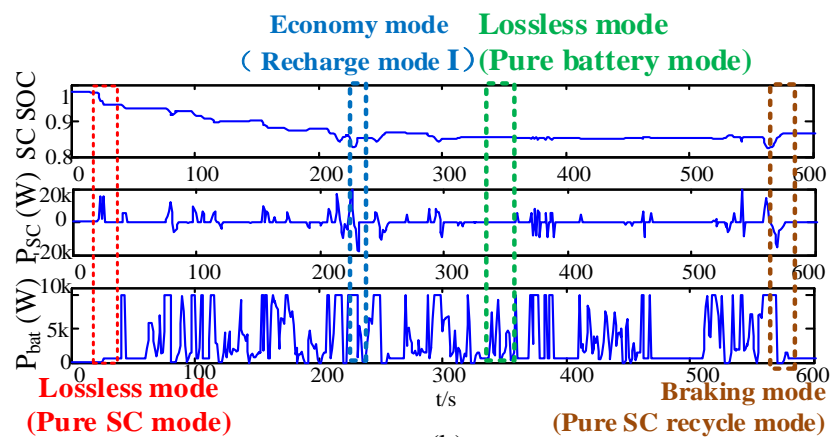

(b) Simulation results in the NYCC (the initial SOC of the SC is 0.98).

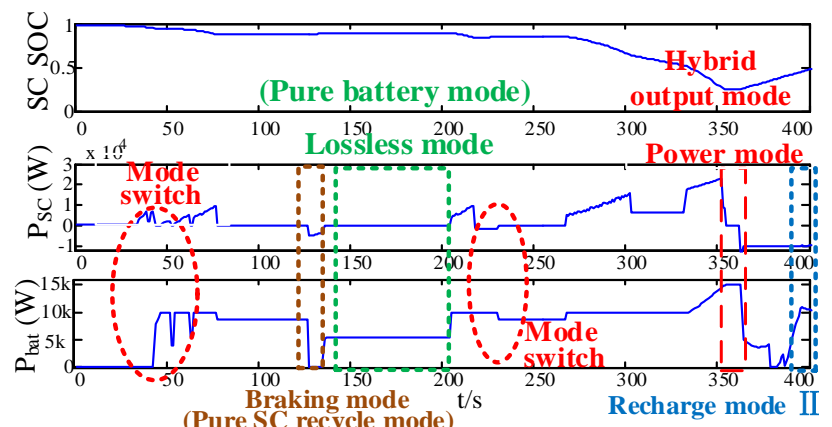

(c) Simulation results in the EUDC (the initial SOC of the SC is 0.98).
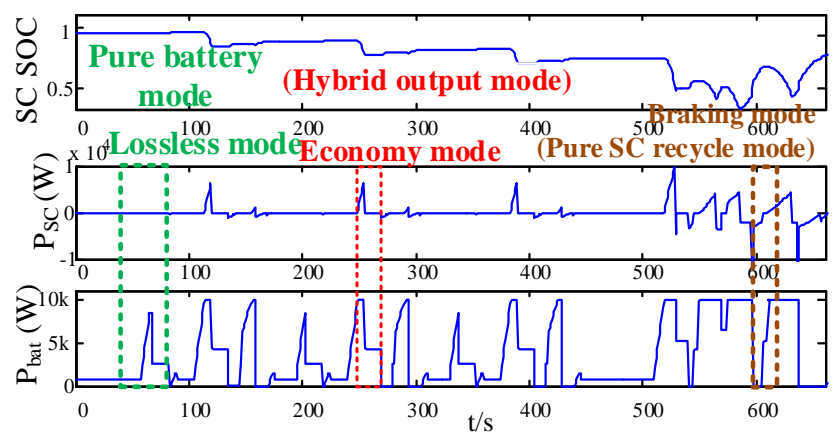

(d) Simulation results in the J1015 (the initial SOC of the SC is 0.98).

Fig. 11. Simulation results.

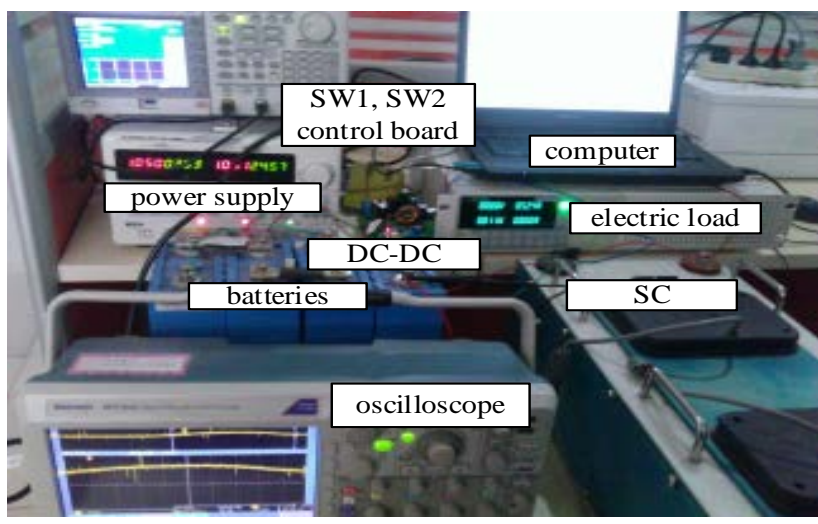

Fig. 12. Experimental platform.

TABLE III

IMPORTANT PARAMETERS OF THE EXPERIMENTAL PLATFORM

\begin{tabular}{|c|c|}
\hline Items & Values \\
\hline Electronic load & 150 V (KL6101 100 A, 1200 W Max) \\
\hline Power supply & 32 V (IPD3305-SLU 5.2 A, 0.03\%) \\
\hline SC & Limited as $25 \mathrm{~V}$ (Kaimai $76 \mathrm{~V} 94 \mathrm{~F}$ ) \\
\hline Batteries & 12.8 V (HuanYu 3.2 V 80 Ah in series) \\
\hline $\begin{array}{l}\text { DC-DC } \\
\text { converter }\end{array}$ & Peak efficiency region: (90 W to $110 \mathrm{~W}$ ) \\
\hline
\end{tabular}

experimental platform is depicted in Fig. 12, and the important parameters of the platform components are listed in Table III. Fig. 13 displays the comprehensive results.

Figs. 13(a) and 13(b) illustrate the comparative results of the compound-type HESS with 1/100 power demand in the NYCC. The lossless mode switches to economy mode when the initial SC voltage drops from $25 \mathrm{~V}$ to $23.5 \mathrm{~V}$. This occurrence is in accordance with the initial SOC of SC, which also decreased from 1 to 0.95 . The DC-DC converter operates in boost mode within its peak efficiency region when the economy mode is implemented. The lossless and braking modes are implemented without the DC-DC converter, and no energy is supplied directly to the batteries. The experimental results are in accordance with the simulation results, thus demonstrating that the high efficiency of the DC-DC converter and the satisfactory performance of the compound-type HESS. Meanwhile, the power output of the batteries is maintained at an appropriate level to extend battery life. These results also demonstrate the mode control strategy of the economy, lossless, and braking modes.

Fig. 13(c) presents the experimental results of the compound-type HESS with 1/100 power demand in the EUDC. Power demand is high to verify the power mode and recharge mode II. The SC voltage drops quickly, and either of the two aforementioned modes is implemented when the SOC of the SC is less than 0.5. The power mode ensures the power supply to the compound-type HESS; this process is important 


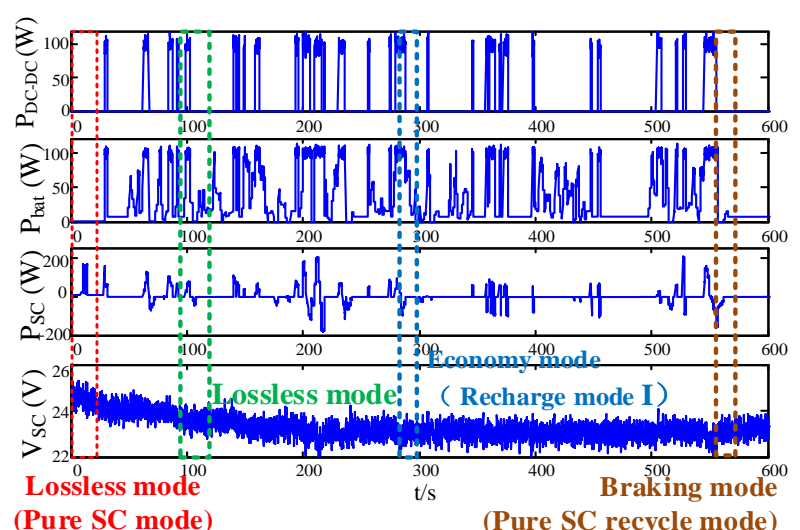

(a) Experimental results in the NYCC when initial SC voltage is set to $25 \mathrm{~V}$.

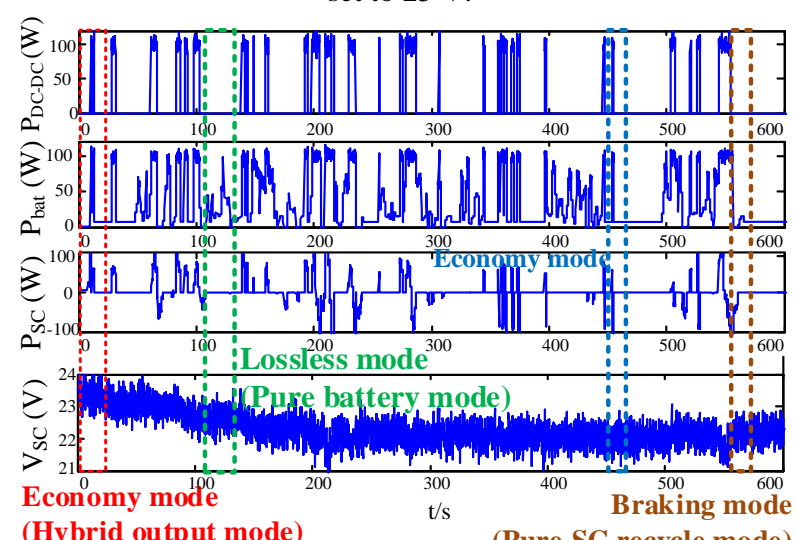

(Hybrid output mode) (Pure SC recycle mode)

(b) Experimental results in the NÝC when initial SC voltage is set to $23.5 \mathrm{~V}$.

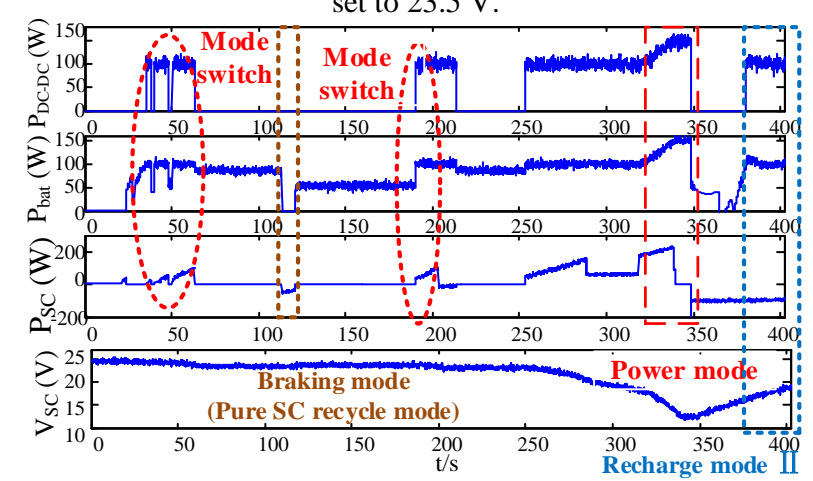

(c) Experimental results in the EUDC when initial SC voltage is set to $25 \mathrm{~V}$.

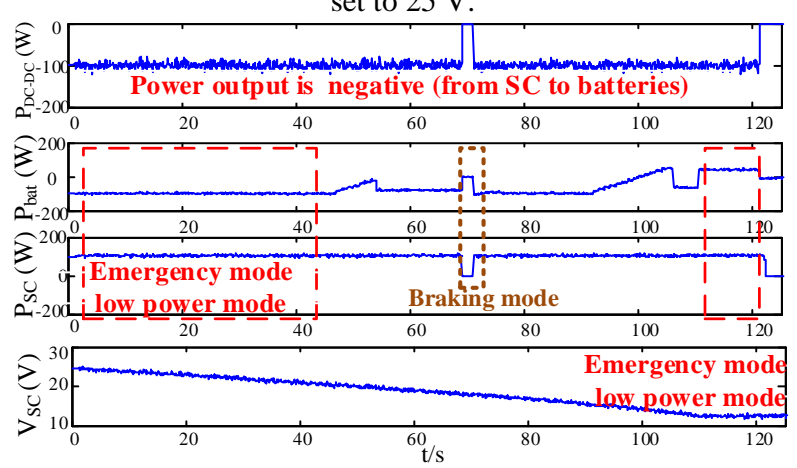

(d) Experimental results in the J1015 ( $0 \mathrm{~s}$ to $120 \mathrm{~s}$ ) when the initial SC voltage is set to $25 \mathrm{~V}$.

Fig. 13. Comprehensive results with $1 / 100$ power demands in the three driving cycles.
TABLE IV

COMPARATIVE RESULTS

\begin{tabular}{c|c|c|c|c|c|c}
\hline \multirow{2}{*}{$\begin{array}{c}\text { Driving } \\
\text { cycles }\end{array}$} & \multicolumn{3}{|c|}{$\begin{array}{c}\text { Energy losses in DC-DC } \\
\text { converters }\end{array}$} & \multicolumn{3}{|c}{$\begin{array}{c}\text { Overall system efficiency } \\
\text { of HESSs }\end{array}$} \\
\cline { 2 - 7 } & $\begin{array}{c}\text { Com- } \\
\text { type }\end{array}$ & $\begin{array}{c}\text { battery } \\
\text { /SC }\end{array}$ & $\begin{array}{c}\text { SC/ } \\
\text { battery }\end{array}$ & $\begin{array}{c}\text { Com- } \\
\text { type }\end{array}$ & $\begin{array}{c}\text { battery } \\
\text { /SC }\end{array}$ & $\begin{array}{c}\text { SC/ } \\
\text { battery }\end{array}$ \\
\hline NYCC & $4.3 \%$ & $9.1 \%$ & $8.6 \%$ & $92.3 \%$ & $90.7 \%$ & $91.3 \%$ \\
\hline EUDC & $7.2 \%$ & $9.1 \%$ & $12.3 \%$ & $91.1 \%$ & $90.7 \%$ & $87.5 \%$ \\
\hline
\end{tabular}

because the SC can provide only limited energy and should be recharged in this condition. The results demonstrate the mode control strategies of the power mode and of recharge mode II. Moreover, the compound-type HESS is well-balanced in terms of high efficiency and high power output.

Fig. 13(d) shows the experimental results of the compound-type HESS with 1/100 power demand in the J1015. The initial battery voltage is less than $10.8 \mathrm{~V}$; thus, battery SOC is less than 0.1. A time limit ( $0 \mathrm{~s}$ to $120 \mathrm{~s})$ is set for the experiment because the $\mathrm{SC}$ can provide less energy to charge batteries after $120 \mathrm{~s}$. The low power mode is utilized if the SC supplies adequate power. Furthermore, the batteries are recharged if the power output of the DC-DC converter is higher than the power demanded by the electronic load. Otherwise, the batteries should provide power to the electronic load. The results demonstrate the emergency mode as well.

To enhance the effectiveness of analysis, the compound-type, the battery/SC [33], and the SC/battery [31] HESSs are implemented along with their control strategies given $1 / 100$ of the power demands in the NYCC and in the EUDC. The comparative results of the three HESSs are listed in Table IV. The energy losses in the DC-DC converter of the compound-type HESS are limited in both the NYCC and the EUDC. In addition, this HESS presents a better performance in terms of overall system efficiency. The energy losses of the DC-DC converter in the EUDC are higher than those in the NYCC because the power mode is activated. Meanwhile, overall system efficiency does not accord with the energy losses in the DC-DC converter because the compound-type HESS incurs additional energy loss in SW1 and SW2. Nonetheless, the battery/SC and the SC/battery HESSs operate without energy loss in SW1 and SW2. Therefore, the process of reducing this type of energy loss will be studied in the future.

Although the compound-type HESS experiences additional drawbacks, the comparative results suggest that this HESS can reduce energy losses in the DC-DC converter in addition to extending battery life. The compound-type HESS also reports high overall system efficiency. Specifically, the efficiency of the compound-type HESS is up to $1.6 \%$ and $1 \%$ higher than that of the battery/SC and of the SC/battery HESSs in the NYCC, respectively. The corresponding efficiencies under EUDC are $0.4 \%$ and 3.6\%. 


\section{CONCLUSION}

A novel compound-type HESS is proposed in this paper. The proposed HESS is uniquely advantageous over the conventional HESS in terms of both battery/SC and the SC/battery HESS configurations. The compound-type HESS is designed with eight operation modes, and five classes of these modes are highlighted to simplify mode control strategy. This strategy focuses on both the high operating efficiency and the high power output of the compound-type HESS. Therefore, the DC-DC converter usually operates at peak efficiency to transmit energy from the batteries to the SC. Mode control strategy merely increases power output to the motor inverter when power demand must constantly be high. In addition, the SC is designed as the top priority in terms of braking energy absorption. Thus, the batteries are prevented from direct recharging to extend battery life during regenerative braking.

The model of the compound-type HESS and its mode control strategy was simulated. The simulation results showed that the compound-type HESS and its mode control strategy can not only provide adequate power to the motor inverter, but they can also determine suitable operation modes under corresponding conditions. This scenario can improve HESS efficiency and extend battery life. A scaled-down platform was also constructed for the experiment conducted. The experimental results were in accordance with the simulation results and effectively demonstrated the mode control strategy of the compound-type HESS. This HESS can limit the power output of the batteries. Furthermore, the batteries were prevented from direct recharge during regenerative braking. Thus, battery life is extended. In addition, the experimental results demonstrated that the compound-type HESS can reduce energy losses in the DC-DC converter significantly. The overall system efficiency of the proposed HESS is up to $1.6 \%$ and $1 \%$ higher than that of the battery/SC and of the SC/battery HESSs in the NYCC, respectively. The corresponding values are $0.4 \%$ and $3.6 \%$ in the EUDC.

\section{ACKNOWLEDGMENT}

This work was supported by the National Natural Science Foundation of China (Grant No. 51405374) and the Postdoctoral Science Foundation of China (Grant No. 2014M560763).

\section{REFERENCES}

[1] Z. Song, J. Li, X. Han, L. Xu, L. Lu, M. Ouyang, and H. Hofmann, "Multi-objective optimization of a semi-active battery/supercapacitor energy storage system for electric vehicles,” Applied Energy, Vol. 135, pp. 212-224, Dec. 2014.
[2] B.-H. Lee, D.-H. Shin, H.-S. Song, H. Heo, and H.-J. Kim, "Development of an advanced hybrid energy storage system for hybrid electric vehicles," Journal of Power Electronics, Vol. 9, No. 1, pp. 51-60, Jan. 2009.

[3] Y. Zhang, C. H. Zhang, and X. F. Zhang, "State-of-charge estimation of the lithium-ion battery system with time-varying parameter for hybrid electric vehicles," IET Control Theory \& Applications, Vol. 8, No. 3, pp. 160-167, Feb. 2014.

[4] L. Xian, G. Wang, and Y. Wang, "Subproportion control of double input buck converter for fuel cell/battery hybrid power supply system,” IET Power Electronics, Vol. 7, No. 8, pp. 2141-2150, Aug. 2014.

[5] S. F. Tie and C. W. Tan, "A review of energy sources and energy management system in electric vehicles," Renewable and Sustainable Energy Reviews, Vol. 20, pp. 82-102, Apr. 2013.

[6] J. Cao and A. Emadi, “A new battery/ultracapacitor hybrid energy storage system for electric, hybrid, and plug-in hybrid electric vehicles," IEEE Trans. Power Electron., Vol. 27, No. 1, pp. 122-132, Jan. 2012.

[7] A. Khaligh and Z. Li, "Battery, ultracapacitor, fuel cell, and hybrid energy storage systems for electric, hybrid electric, fuel cell, and plug-in hybrid electric vehicles: State of the art,” IEEE Trans. Veh. Technol., Vol. 59, No. 6, pp. 2806-2814, Jul. 2010.

[8] R. Adany, D. Aurbach, and S. Kraus, "Switching algorithms for extending battery life in Electric Vehicles," Journal of Power Sources, Vol. 231, pp. 50-59, Jun. 2013.

[9] J. Xu, C. C. Mi, B. Cao, and j. Cao, “A new method to estimate the state of charge of lithium-ion batteries based on the battery impedance model," Journal of Power Sources, Vol. 233, pp. 277-284, Jul. 2013.

[10] J. Xu, S. Li, C. Mi, Z. Chen, and B. Cao, "SOC based battery cell balancing with a novel topology and reduced component count,” Energies, Vol. 6, No. 6, pp. 2726-2740, May 2013.

[11] J. M. Blanes, R. Gutierrez, A. Garrigos, J. L. Lizan, and J. M. Cuadrado, "Electric vehicle battery life extension using ultracapacitors and an FPGA controlled interleaved buck-boost converter," IEEE Trans. Power Electron., Vol. 28, No. 12, pp. 5940-5948, Dec. 2013.

[12] J. Moreno, M. E. Ortúzar, and J. W. Dixon, "Energy-management system for a hybrid electric vehicle, using ultracapacitors and neural networks," IEEE Trans. Ind. Electron., Vol. 53, No. 2, pp. 614-623, Apr. 2006.

[13] Z. Song, H. Hofmann, J. Li, J. Hou, X. Han, and M. Ouyang, "Energy management strategies comparison for electric vehicles with hybrid energy storage system," Applied Energy, Vol. 134, pp. 321-331, Dec. 2014.

[14] H. Jung, H. F. Wang, and T. S. Hu, "Control design for robust tracking and smooth transition in power systems with battery/supercapacitor hybrid energy storage devices," Journal of Power Sources, Vol. 267, pp. 566-575, Dec. 2014.

[15] H.-S. Song, J.-B. Jeong, D.-H. Shin, B.-H. Lee, H.-J. Kim, and $\mathrm{H}$. Heo, "Dynamic SOC compensation of an ultracapacitor module for a hybrid energy storage system," Journal of Power Electronics, Vol. 10, No. 6, pp. 769-776, Nov. 2010

[16] B. Long, S. T. Lim, Z. F. Bai, J. H. Ryu, and K. T. Chong, "Energy management and control of electric vehicles, using hybrid power source in regenerative braking operation,” Energies, Vol. 7, No. 7, pp. 4300-4315, Jul. 2014. 
[17] J. P. F. Trovao, V. D. N. Santos, P. G. Pereirinha, H. M. Jorge, and C. H. Antunes, "A simulated annealing approach for optimal power source management in a small EV,” IEEE Trans. Sustain. Energy, Vol. 4, No. 4, pp. 867-876, Oct. 2013.

[18] H. Liu, Z. Wang, J. Cheng, and D. Maly, "Improvement on the cold cranking capacity of commercial vehicle by using supercapacitor and lead-acid battery hybrid," IEEE Trans. Veh. Technol., Vol. 58, No. 3, pp. 1097-1105, Mar. 2009.

[19] L. Solero, A. Lidozzi, and J. A. Pomilio, "Design of multiple-input power converter for hybrid vehicles," IEEE Trans. Power Electron., Vol. 20, No. 5, pp. 1007-1016, Sep. 2005.

[20] B. Hredzak, V. G. Agelidis, and M. Jang, "A model predictive control system for a hybrid battery-ultracapacitor power source," IEEE Trans. Power Electron., Vol. 29, No. 3, pp. 1469-1479, Mar. 2014.

[21] J. Leyva-Ramos, M. Ortiz-Lopez, L. H. Diaz-Saldierna, and M. Martinez-Cruz, "Average current controlled switching regulators with cascade boost converters," IET power electronics, Vol. 4, No. 1, pp. 1-10, Jan. 2011.

[22] F. Ongaro, S. Saggini, and P. Mattavelli, "Li-ion battery-supercapacitor hybrid storage system for a long lifetime, photovoltaic-based wireless sensor network," IEEE Trans. Power Electron., Vol. 27, No. 9, pp. 3944-3952, Sep. 2012.

[23] E. Vinot and R. Trigui, "Optimal energy management of HEVs with hybrid storage system," Energy Conversion and Management, Vol. 76, pp. 437-452, Dec. 2013.

[24] O. Laldin, M. Moshirvaziri, and O. Trescases, "Predictive algorithm for optimizing power flow in hybrid ultracapacitor/battery storage systems for light electric vehicles," IEEE Trans. Power Electron., Vol. 28, No. 8, pp. 3882-3895, Aug. 2013.

[25] E. Babaei, M. F. Kangarlu, and M. Sabahi, "Extended multilevel converters: an attempt to reduce the number of independent DC voltage sources in cascaded multilevel converters," IET Power Electronics, Vol. 7, No. 1, pp. 157-166, Jan. 2014.

[26] A.-L. Allègre, A. Bouscayrol, and R. Trigui, "Flexible real-time control of a hybrid energy storage system for electric vehicles," IET Electrical Systems in Transportation, Vol. 3, No. 3, pp. 79-85, Sep. 2013.

[27] P. Taesik and K. Taehyung, "Novel Energy Conversion System Based on a Multimode Single-Leg Power Converter," IEEE Trans. Power Electron., Vol. 28, No. 1, pp. 213-220, Jan. 2013.

[28] M. Michalczuk, L. M. Grzesiak, and B. Ufnalski, "A lithium battery and ultracapacitor hybrid energy source for an urban electric vehicle," Electrotechnical Review, Rev.88, pp. 158-162, 2012.

[29] M. B. Camara, H. Gualous, F. Gustin, and A. Berthon, "Design and new control of DC/DC converters to share energy between supercapacitors and batteries in hybrid vehicles,” IEEE Trans. Veh. Technol., Vol. 57, No. 5, pp. 2721-2735, Sep. 2008.

[30] L. Lu, X. Han, J. Li, J. Hua, and M. Ouyang, “A review on the key issues for lithium-ion battery management in electric vehicles," Journal of Power Sources, Vol. 226, pp. 272-288, Mar. 2013.

[31] H. He, R. Xiong, K. Zhao, and Z. Liu, "Energy management strategy research on a hybrid power system by hardware-in-loop experiments," Applied Energy, Vol. 112, pp. 1311-1317, Dec. 2013.
[32] A. Kuperman, I. Aharon, S. Malki, and A. Kara, "Design of a semiactive battery-ultracapacitor hybrid energy source," IEEE Trans. Power Electron., Vol. 28, No. 2, pp. 806-815, Feb. 2013.

[33] C. Xiang, Y. Wang, S. Hu, and W. Wang, "A new topology and control strategy for a hybrid battery-ultracapacitor energy storage system,” Energies, Vol. 7, No. 5, pp. 2874-2896, Apr. 2014.

[34] X. Hu, L. Johannesson, N. Murgovski, and B. Egardt, "Longevity- conscious dimensioning and power management of the hybrid energy storage system in a fuel cell hybrid electric bus,” Applied Energy, Vol. 137, pp. 913-924, Jan. 2014

[35] Z. Zou, J. Xu, C. Mi, B. Cao, and Z. Chen, "Evaluation of model based state of charge estimation methods for lithium-ion batteries," Energies, Vol. 7, No. 8, pp. 5065-5082, 2014.

[36] J. Xu, C. C. Mi, B. Cao, J. Deng, Z. Chen, and S. Li, “The state of charge estimation of lithium-ion batteries based on a proportional integral observer," IEEE Trans. Veh. Technol., Vol. 63, No. 4, pp. 1614-1621, May 2014.

[37] V. Johnson, "Battery performance models in ADVISOR," Journal of power sources, Vol. 110, No. 2, pp. 321-329, Aug. 2002.

[38] L. Zubieta and R. Bonert, "Characterization of double-layer capacitors for power electronics applications,” IEEE Trans. on Industry Applications, Vol. 36, No. 1, pp. 199-205, Jan. 2000.

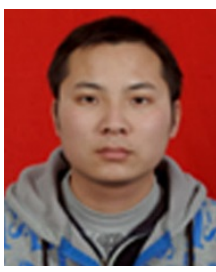

Bin Wang was born in Guangxi, China, in 1987. He received his BS and MS degrees in 2010 and 2013, respectively, from the Information Engineering College, Henan University of Science and Technology, Luoyang, China. He is currently working toward his $\mathrm{PhD}$ at the School of Mechanical Engineering, Xi'an Jiaotong University. His research interests include energy storage systems, hybrid energy storage systems, electric vehicles, DC-DC converter control, and supercapacitor SOC estimation.

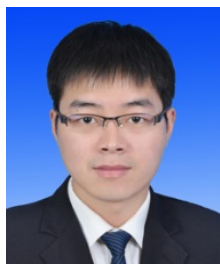

Jun $\mathrm{Xu}$ received his $\mathrm{BS}$ and $\mathrm{PhD}$ degrees in Mechanical Engineering from Xi'an Jiaotong University, Xi'an, Shaanxi, China in 2009 and 2013, respectively. He is an assistant professor at the Institute for Electric Vehicle and System Control in Xi'an Jiaotong University. His research interests include energy system design, analysis, testing, and state estimation for

electric vehicles.

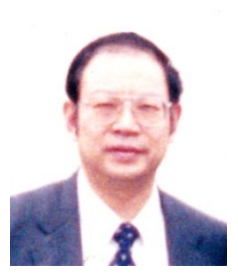

Binggang Cao received his $\mathrm{PhD}$ from Xi'an Jiaotong University, Xi'an, China. He is a professor and the director of the Institute for Electric Vehicle and System Control in Xi'an Jiaotong University, where he was once the dean of the School of Mechanical Engineering and the director of the Research Center for Electric Vehicles. His research interests include system optimization, mechatronic systems, electric vehicles, electric drive systems, electric vehicle demonstration, and infrastructure. 




Qiyu $\mathbf{L i}$ received his BS degree in Mechanical Engineering and Automation from Xi an Polytechnic University, Xi'an, China, in 2010. He received his MS in Mechanical Engineering from Xi'an Jiaotong University, Xi'an, China, in 2014. He is presently a PhD candidate at the School of Mechanical Engineering, Xi'an Jiaotong University, Xi'an, China. His research interests are the design and the optimization of photovoltaic systems.

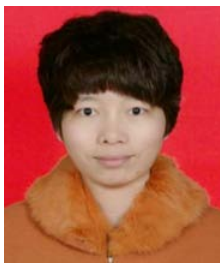

Qingxia Yang was born in Henan, China, in 1988. She received her BS and MS degrees from the School of Mechanical Engineering, Henan University of Science and Technology, Luoyang, China, in 2010 and 2013, respectively. She is currently working toward her $\mathrm{PhD}$ degree at the School of Mechanical Engineering, Xi'an Jiaotong University. Her research interests include battery management systems, hybrid electric vehicles, and battery SOC estimation. 